\title{
Spatial iconicity affects semantic relatedness judgments
}

\author{
ROLF A. ZWAAN and RICHARD H. YAXLEY \\ Florida State University, Tallahassee, Florida
}

\begin{abstract}
Three experiments were conducted to examine whether spatial iconicity affects semantic-relatedness judgments. Subjects made speeded decisions with regard to whether members of a simultaneously presented word pair were semantically related. In Experiment 1, the words were presented one above the other. In the experimental pair, the words denoted parts of larger objects (e.g., ATTIC-BASEMENT). The words were either in an iconic relation with their referents (e.g., ATTIC presented above BASEMENT) or in a reverse-iconic relation (BASEMENT above ATTIC). The reverse-iconic condition yielded significantly slower semantic-relatedness judgments than did the iconic condition. Experiments 2 and 3 showed that this effect did not occur when the words were presented horizontally, thus ruling out that the iconicity effect is due to the order in which the words are read. Two alternative explanations for this finding are discussed.
\end{abstract}

In 1918, the French poet Guillaume Apollinaire published a volume of poetry called Calligrammes. In it, he experimented with typography in such a way that it showed an analogical relation to its content. For instance, the famous poem "Il pleut" (It is raining) was printed to resemble falling rain. Thus, this type of concrete poetry is characterized by the fact that the representation of the words on the page bears an iconic relation to (an aspect of) the situation that the poem presents. Iconicity occurs when a linguistic sign has an analog relation to its referent (Peirce, 1992).

A simple example of iconicity consists in onomatopoeia, words that sound the same as their referent (e.g., cuckoo). However, iconicity may also occur at a higher level of abstraction, as in Caesar's famous dictum "veni, vidi, vici" (I came, I saw, I conquered), in which the linear order of the words matches the chronological order of the events that they describe (Jakobson, 1971). Psychological studies have shown that violations of such temporal iconicity affect online processing. Specifically, when words or clauses are presented in an order that is inconsistent with the order of the events to which they refer (e.g., Before the manager went to the meeting, he made a phone call), some momentary difficulty in processing them ensues (Mandler, 1986; Münte, Schiltz, \& Kutas, 1998). A similar effect occurs when events that are distant in time are reported consecutively in a text (Rinck \& Bower, 2000; Zwaan, 1996).

The goal of our present study was to examine whether not only temporal iconicity, but also spatial iconicity-

This research was supported by Grant MH-63972 to R.A.Z. We thank the reviewers for helpful comments. Please address all correspondence regarding this paper to R. A. Zwaan, Department of Psychology, Florida State University, Tallahassee, FL 32306-1270(e-mail: zwaan@psy.fsu.edu). specifically, the relative positions of words on a computer screen as compared with the relative positions of their referents-affects language processing. Research on the "spatial Stroop effect" suggests an affirmative answer to this question. In a spatial Stroop task, words denoting locations (e.g., ABOVE-BELOW, LEFT-RIGHT) are presented in locations on a computer screen that either are (e.g., the word BELOW presented below a fixation point) or are not (e.g., the word LEFT presented on the right of a fixation point) consistent with their meaning. There is extensive evidence that a mismatch between a word's meaning and its location leads to an increase in response times relative to a control condition, just as the mismatch between the color in which a word is presented and its meaning produces the "regular" Stroop effect $(\mathrm{Lu}$ \& Proctor, 1995; MacLeod, 1991; White, 1969).

In the spatial Stroop task, the stimuli are prepositions that explicitly denote a location, which then matches or mismatches the actual location of the word in a display (e.g., a computer screen). Thus, the verbal cues are deictic terms referring to the subjects' (and the words'!) immediate environment. A major focus in language comprehension research is on the use of language in the construction of referential representations of situations not in the subjects' immediate environment (e.g., Zwaan \& Radvansky, 1998). If it could be demonstrated that spatial-Stroop-like effects could be obtained in imagined environments, this would be informative with respect to the mental representation of their referents.

In the present study, we used nouns denoting (parts of) objects whose canonical spatial relation is vertical (e.g., BRANCH-ROOT, ATTIC-BASEMENT, NOSE-MOUTH, Or FLAMECANDLE), but which do not make direct reference to a spatial location. The critical manipulation consisted in varying the spatial arrangement of the words to be either 
consistent with the arrangement of their referents as in $(1)$, or not, as in (2):

(1) BRANCH ROOT

(2) ROOT

\section{BRANCH}

If spatial arrangement affects interpretation, the consistent condition should yield faster responses than those for the reversed-iconic condition. To test this hypothesis, we presented such word pairs on a computer screen to subjects who judged whether the members of each pair were semantically related. This semantic judgment task was selected because it would encourage the subjects to consider the relation between the words' referents (e.g., unlike in a naming task) without explicitly calling for a spatial alignment of the two referents, which might have clued the subjects in on the manipulation.

\section{EXPERIMENT 1}

\section{Method}

Subjects. Thirty-six Florida State University undergraduates were recruited from several general psychology classes in exchange for academic course credit.

Design. The main factor in the design was match, with two levels (match vs. mismatch), which was varied within subjects and within items. The items were counterbalanced across two lists. The list factor was manipulated between subjects and items and was used in the analyses reported below only in the explanation of error variance.

Materials. The 28 experimental word pairs consisted of the names of common objects or parts of objects that are canonically viewed in a fixed vertical relation; for instance, branches are above roots in the canonical view of a tree and an attic is above a basement in the canonical view of a house. The items were counterbalanced across two lists. Each participant saw one of two lists that included 14 word pairs that matched and 14 word pairs that mismatched the canonical vertical orientation of their referents. The 60 filler items were not constrained with respect to vertical orientation. Rather, the words were matched by semantic relatedness - for instance, by being members of the same superordinate category (APPLE-PEAR) or a lack thereof. There were 30 semantically related filler items, and 30 semantically unrelated filler items. The experimental items were nouns of one to three syllables in length, with an average length of 5.2 letters. The words were presented in black font and subtended at most $0.42^{\circ}$ of vertical visual angle from a distance of $55 \mathrm{~cm}$.

We entered our item pairs into the latent semantic indexing database (http://lsa.colorado.edu) to obtain an independent assessment of their semantic relatedness. Latent semantic analysis (LSA) is a mathematical/statistical technique for extracting and representing the similarity of meaning of words and passages by analysis of large bodies of text (Landauer \& Dumais, 1997). The degree of semantic relatedness of a word pair is operationalized as the cosine of the contained angle of the vectors representing the meanings of words. We used LSA's pairwise comparison function, the General-Readingup-to-1st-year-in-college-database, and the default number of factors. The average cosines were .44 for the experimental pairs, .41 for the semantically related filler pairs, and .08 for the semantically unrelated filler pairs. A one-way analysis of variance (ANOVA) yielded a significant effect of item type $[F(2,86)=36.56, p<$
.0001]. Post hoc Scheffé tests revealed that the cosine for the semantically unrelated items was significantly lower than those of the other two groups of items, which did not differ significantly from one another. ${ }^{1}$

Procedure. The stimuli were presented with a Macintosh PowerPC on a 14-in. display using PsyScope software (Cohen, MacWhinney, Flatt, \& Provost, 1993). The subjects were instructed that they would see pairs of words that were either related or unrelated in meaning. They were informed that the relation or lack of relation should be obvious, because the items were not meant to be confusing. The subjects were instructed to keep their fingers positioned on the response keys at all times during the experiment, and to respond as quickly and accurately as possible by pressing the $\mathrm{Y}$ and $\mathrm{N}$ labeled keys (the $\mathrm{X}$ and the period keys). Responses not made within $2 \mathrm{sec}$ after stimulus presentation were logged as incorrect and the following trial was cued. These messages were displayed only during the initial practice trials, to encourage timely responses for the experimental items.

The subjects controlled the intertrial interval and initiated each trial with a keypress. We attempted to control the location of eye fixation at the beginning of each trial by presenting a fixation cross for $250 \mathrm{msec}$. Then each word pair was displayed in the center of the screen. Each word pair subtended $1.35^{\circ}$ of vertical visual angle at a viewing distance of $55 \mathrm{~cm}$. Response latencies and semanticrelatedness decisions to these word pairs were recorded by the computer. The experiment took approximately $10 \mathrm{~min}$.

\section{Results and Discussion}

In all three experiments reported below, we used the following criteria. All analyses were based on data from subjects with accuracy scores of $>85 \%$. Reaction times three standard deviations from each subject's condition mean were excluded from the analysis, as were times that were $<550 \mathrm{msec}$; this affected less than $2 \%$ of the observations in each of the experiments. Although we had made an effort to avoid including word pairs that have a canonical order in the language, the pair BREAD-BUTTER had slipped by our attention. It was eliminated from the analyses in all three experiments. Furthermore, because of a programming error, one of the test words in Experiments 1 and 2 (CHIMNEY) was paired up with two different words (SMOKE and FIRE) across different lists and could therefore not be used. The experimental items that ended up being used are shown in Appendix A. In all three experiments, analyses were conducted with subjects (indicated by the subscript 1 ) and items (indicated by the subscript 2 ) as the random factor. The stimuli were presented in lists, which were counterbalanced across conditions. List was included as a between-subjects factor in the statistical analyses if it interacted significantly with the factors of interest.

The average response times and accuracy scores are shown in Table 1. Mixed ANOVAs with match as the within-subjects and within-items factor and list as the between-subjects factor showed that this difference was significant $\left[F_{1}(1,34)=5.77, M S_{\mathrm{e}}=8,487, p<.025\right.$; $\left.F_{2}(1,24)=6.51, M S_{\mathrm{e}}=6,591, p<.025\right]$. The accuracy scores show that there was no speed-accuracy tradeoff, with the match condition being, if anything, more accurate than the mismatch condition $\left(F_{\mathrm{s}}<3.23, p \mathrm{~s}>.08\right)$. The related filler items produced faster responses than did the experimental items ( $p$ s $<.01)$, presumably be- 
Table 1

Semantic Judgment Latencies and Accuracy by Stimulus-Pair Orientation for the Three Experiments

\begin{tabular}{|c|c|c|c|c|c|c|c|c|c|c|c|c|c|c|c|c|}
\hline \multirow{3}{*}{ Experiment } & \multicolumn{8}{|c|}{ Vertical } & \multicolumn{8}{|c|}{ Horizontal } \\
\hline & \multicolumn{4}{|c|}{ Experimental } & \multicolumn{4}{|c|}{ Filler } & \multicolumn{4}{|c|}{ Experimental } & \multicolumn{4}{|c|}{ Filler } \\
\hline & \multicolumn{2}{|c|}{ Match } & \multicolumn{2}{|c|}{ Mismatch } & \multicolumn{2}{|c|}{ Related } & \multicolumn{2}{|c|}{ Unrelated } & \multicolumn{2}{|c|}{ Match } & \multicolumn{2}{|c|}{ Mismatch } & \multicolumn{2}{|c|}{ Related } & \multicolumn{2}{|c|}{ Unrelated } \\
\hline 1 & 1,117 & 92 & 1,169 & 89 & 1,072 & 89 & 1,282 & 91 & & & & & & & & \\
\hline 2 & & & & & & & & & 1,169 & 94 & 1,181 & 93 & 1,091 & 89 & 1,244 & 91 \\
\hline 3 & 1,131 & 94 & 1,184 & 93 & 1,037 & 93 & 1,319 & 93 & 1,215 & 93 & 1,207 & 95 & 1,111 & 93 & 1,377 & 91 \\
\hline
\end{tabular}

cause they were controlled for relatedness relative to the experimental items, but they tended to be shorter. The unrelated fillers yielded longer response times than did the other items because they required "no" responses.

The main result can be interpreted as support for the hypothesis that the spatial arrangement of the words affects their interpretation. However, an alternate interpretation of these results presents itself. It is likely that the words of each pair were always read from top to bottom. Thus, spatial arrangement was confounded with temporal order. Therefore, the possibility exists that the order in which the words were read is responsible for the effect. There are two separate reasons why this hypothesis is plausible. First, one might argue that perceptual simulations (Barsalou, 1999) of objects based on verbal descriptions are usually constructed from top to bottom, just as we often scan objects visually from top to bottom. Because the mismatch condition was at odds with this hypothetical default scanning process, it might have led to longer response times than those in the match condition. Second, despite our efforts to select word pairs that did not have a canonical order in the language (e.g., HEAD and HEELS in head over heels), we might not have been completely successful. To address these questions, we conducted Experiment 2, in which we simply presented the word pairs horizontally. If the hypotheses just described were correct, we should obtain a mismatch effect similar to that found in Experiment 1.

\section{EXPERIMENT 2}

\section{Method}

Subjects. Forty Florida State University undergraduates were recruited from several general psychology classes in exchange for academic course credit.

Stimuli and Design. The stimuli and design were identical to those for Experiment 1 . The only difference was that the word pairs were presented horizontally, depending on the experimental condition. Thus, all "top" words were presented to the left and "bottom" words to the right of the fixation cross.

Procedure. The procedure was identical to that for Experiment 1, with the exception of stimulus location. The visual angle did vary between the right- and leftmost letters as the 1-cm distance between words remained unchanged. On average, the rightmost letter of a word to the right of the fixation cross or the leftmost letter of a word to the left of the fixation cross subtended $2.08^{\circ}$ of visual angle from the fixation point, at a viewing distance of $55 \mathrm{~cm}$.

\section{Results and Discussion}

The average response times and accuracy scores are shown in Table 1. Mixed ANOVAs with match as the within-subjects and within-items factor and list as the between-subjects factor showed that this difference was not significant (both $F_{\mathrm{S}}<1$ ). The accuracy data also showed no significant effect $\left(F_{\mathrm{S}}<1\right)$. The filler items showed the same pattern as in Experiment 1.

Accepting these results as support for the hypothesis that the spatial location of words affects their processing amounts to accepting the null hypothesis. Therefore, we directly compared the results of Experiments 1 and 2 in a cross-experiment comparison to examine whether or not spatial orientation differentially affected the mismatch effect. The predicted interaction between experiment (i.e., orientation) and match failed to reach significance $\left[F_{1}(1,74)=2.00, M S_{\mathrm{e}}=7,650, p=.16 ; F_{2}(1,24)=\right.$ 3.24, $\left.M S_{\mathrm{e}}=4,994, p<.09\right]$. To test more directly for an interaction between match and orientation, we decided to manipulate these two factors within subjects as well as within items in Experiment 3.

\section{EXPERIMENT 3}

\section{Method}

Subjects. Forty-eight Florida State University undergraduates were recruited from several general psychology classes in exchange for academic course credit.

Stimuli and Design. The set of stimulus items from Experiment 1 was expanded to 64 experimental pairs. In addition, the set of filler items was expanded to 128 . Thirty-two filler pairs were semantically related, and the remaining 96 were not. The experimental items were nouns ranging from one to four syllables long, with an average length of 5.7 letters. They are shown in Appendix B. The two main factors, both manipulated within subjects and within items, were match and orientation. The items were counterbalanced across four lists.

We used the same LSA procedure as in Experiment 1 for this expanded set of materials to independently validate the semantic relatedness of our stimulus pairs. The average cosines were .39 for the experimental pairs, .43 for the semantically related filler pairs, and .07 for the semantically unrelated filler pairs. A one-way ANOVA yielded a significant effect of item type $[F(2,164)=82.85, p<.0001]$. Post hoc Scheffé tests revealed that the cosine for the semantically unrelated items was significantly lower than those of the other two groups of items, which did not differ significantly from one another.

Procedure. The procedure was identical to that in Experiment 1, with the exception that the stimuli were presented in either a vertical or a horizontal arrangement. A blocked presentation (a vertical block followed by a horizontal block, or vice versa) was used, and before each block, subjects were told whether the items were going to be presented horizontally or vertically. This was done to prevent subjects' being confused about the orientation of the upcoming word pairs, which would have produced considerable noise, as pilot testing had revealed. 


\section{Results and Discussion}

Three subjects had accuracy percentages lower than $85 \%$; their data were excluded from further analysis. The average response times and accuracy scores are shown in Table 1. There was no main effect of match $\left[F_{1}(1,42)=\right.$ $\left.3.49, M S_{\mathrm{e}}=6,325, p<.07 ; F_{2}<1\right]$. There was a main effect of orientation $\left[F_{1}(1,42)=4.39, M S_{\mathrm{e}}=28,302, p<\right.$ $\left..05 ; F_{2}(1,57)=10.35, M S_{\mathrm{e}}=9,318, p<.005\right]$, showing that the word pairs were judged more quickly in the vertical orientation than in the horizontal orientation. Most important, the interaction between these two factors was significant $\left[F_{1}(1,42)=4.10, M S_{\mathrm{e}}=9,580, p<.05\right.$; $\left.F_{2}(1,58)=17.08, M S_{\mathrm{e}}=8,444, p<.001\right]$. As in the two previous experiments, there was a significant mismatch effect in the vertical condition $\left[F_{1}(1,42)=7.53, M S_{\mathrm{e}}=\right.$ $\left.7,981, p<.01 ; F_{2}(1,58)=5.39, M S_{\mathrm{e}}=15,918, p<.025\right]$, but not in the horizontal condition (both $F \mathrm{~s}<1.55$ ). Analysis of the accuracy data yielded no significant effects (all $F \mathrm{~s}<2.16, p \mathrm{~s}>.15$ ). The filler items show the same pattern as in the two previous experiments. The main result of this experiment conclusively limits the mismatch effect to the vertical condition.

\section{GENERAL DISCUSSION}

Our results show that the spatial arrangement of word pairs can have an impact on semantic relatedness judgments about the members of each pair when these words denote entities that canonically occur in a specific spatial arrangement. Specifically, when the words are presented vertically and their relative positions are at odds with the relative canonical positions of their referents, responses are slower than when the words are presented consistently with the positions of their referents. We were able to rule out that this effect was due to the order in which the words were read. However, it should be noted that it might be premature to discard the mental scanning hypothesis discussed earlier, given that we did not deliberately select stimuli that are normally scanned from top to bottom. It is possible that with a careful selection of materials along these lines, support for the mental scanning hypothesis would be obtained.

What accounts for our findings? We consider two plausible explanations. Both explanations are based on the finding from research on the spatial Stroop effect ( $\mathrm{Lu}$ \& Proctor, 1995; MacLeod, 1991) that the location of a stimulus is encoded even when it is irrelevant to the experimental task. According to the first, amodal, explanation, a spatial "tag" is attached to each word. In a semantic network, a concept like BRANCH would have a link with concepts such as top, given that branches are typically found in the top parts of trees. As a consequence, for the pair in (1), TOP would be attached to BRANCH and вотTOM to ROOT, whereas the reverse would happen in (2). In the case of (2), this would yield a conflict between the spatial tags and the information in semantic memory. This conflict would delay the activation above threshold of the concept pair, thus delaying the response.
A second explanation can be derived from perceptual theories of lexical representation (Barsalou, 1999; Langacker, 1999; Pulvermüller, 1999; Tranel, H. Damasio, \& A. R. Damasio, 1997). According to these ideas, words activate perceptual representations of their referents. Initial evidence supports these ideas (Kellenbach, Wijers, \& Mulder, 2000; Stanfield \& Zwaan, 2001; Zwaan, Stanfield, \& Yaxley, 2002). Some words are selfcontained in that they activate perceptual representations of entire objects (e.g., CAR or HOUSE). On the other hand, words such as ATTIC or ELBOW activate representations of larger units, with attention focused on the region in question. For example, ELBOw would activate the perceptual representation of a person, with an arm as the region of interest and attention focused on the elbow part (Langacker, 1999).

In the context of our experiments, the two words would each activate their corresponding perceptual representations. Thus, according to this explanation, the relative spatial positions of the words in (1) would yield a pattern consistent with the perceptual patterns activated by the words, whereas the stimulus pattern in (2) would be inconsistent with the perceptual representation to be activated, thus delaying the response. Our current data do not allow us to arbitrate between these two plausible explanations. However, a more recent study (Zwaan \& Yaxley, 2003) supports the modal, but not the amodal explanation. In this study, word pairs were presented in a vertical orientation only, as in Experiment 1 here. However, half the experimental pairs were presented to the right visual field (rvf) and thus the left hemisphere (LH) and the other half to the left visual field (lvf) and thus the right hemisphere $(\mathrm{RH})$. The amodal explanation would predict the same pattern for the two hemispheres (a mismatch effect). On the other hand, the modal hypothesis assumes that the RH is primarily involved in perceptual simulations (e.g., Paivio, 1986; Sadoski \& Paivio, 2001). Consistent with the modal hypothesis, we found that the mismatch effect was limited to the RH.

In summary, the present findings show that the similarity between the spatial arrangement of words and that of their referents affects semantic judgments. These findings are consistent with the notion of iconicity (Peirce, 1992) and provide a meaningful extension of the spatial Stroop effect (Lu \& Proctor, 1995; MacLeod, 1991; White, 1969).

\section{REFERENCES}

Barsalou, L.W. (1999). Perceptual symbol systems. Behavioral \& Brain Sciences, 22, 577-660.

Cohen, J. [D.], MacWhinney, B., Flatt, M., \& Provost. J. (1993). PsyScope: An interactive graphic system for designing and controlling experiments in the psychology laboratory using Macintosh computers. Behavior Research Methods, Instruments, \& Computers, 25, 257-271.

JAKOBSON, R. (1971). Selected writings: Vol. 2. Word and language. The Hague: Mouton.

Kellenbach, M. L., Wijers, A. A., \& Mulder, G. (2000). Visual semantic features are activated during the processing of concrete 
words: Event-related potential evidence for perceptual semantic priming. Cognitive Brain Research, 10, 67-75.

LANDAUER, T. K., \& Dumais, S. T. (1997). A solution to Plato's problem: The latent semantic analysis theory of the acquisition, induction, and representation of knowledge. Psychological Review, 104, 211-240.

LANGACKER, R. W. (1999). On subjectification and grammaticization. In J.-P. Koenig (Ed.), Discourse and cognition: Bridging the gap (pp. 71-89). Stanford, CA: CSLI Publications.

Lu, C.-H., \& Proctor, R. W. (1995). The influence of irrelevant location information on performance: A review of the Simon and spatial Stroop effects. Psychonomic Bulletin \& Review, 5, 174-207.

MACLEOD, C. M. (1991). Half a century of research on the Stroop effect: An integrative review. Psychological Bulletin, 109, 163-203.

MANDLER, J. M. (1986). On the comprehension of temporal order. Language \& Cognitive Processes, 1, 309-320.

MÜNTE, T. F., SChiltz, K., \& KutAs, M. (1998). When temporal terms belie conceptual order. Nature, 395, 71-73.

Nelson, D. L., McEvoy, C. L., \& Schreiber, T. A. (1998). The University of South Florida word association, rhyme, and word fragment norms. Available at http://www.usf.edu/FreeAssociation/.

PAIVIO, A. (1986). Mental representations: A dual coding approach. New York: Oxford University Press.

Peirce, C. S. (1992). The essential Peirce: Vol. 1 (1867-1893) (N. Hauser \& C. Kloesel, Eds.). Bloomington: Indiana University Press.

PUlvermüller, F. (1999). Words in the brain's language. Behavioral \& Brain Sciences, 22, 253-336.

RINCK, M., \& BowER, G. H. (2000). Temporal and spatial distance in situation models. Memory \& Cognition, 28, 1310-1320.

SADOSKI, M., \& PAIVIO, A. (2001). Imagery and text: A dual coding theory of reading and writing. Mahwah, $\mathrm{NJ}$ : Erlbaum.

STANFIELD, R. A., \& ZWAAN, R. A. (2001). The effect of implied orientation derived from verbal context on picture recognition. Psychological Science, 12, 153-156.

Tranel, D., Damasio, H., \& Damasio, A. R. (1997). A neural basis for the retrieval of conceptual knowledge. Neuropsychologia, 35, 13191327.

White, B. W. (1969). Interference in identifying attributes and attribute names. Perception \& Psychophysics, 6, 166-168.

ZWAAN, R. A. (1996). Processing narrative time shifts. Journal of Experimental Psychology: Learning, Memory, \& Cognition, 22, 11961207.

ZWAAN, R. A., \& RADVANSKY, G. A. (1998). Situation models in language comprehension and memory. Psychological Bulletin, 123, 162-185.

ZWAan, R. A., StANFIELd, R. A., \& YAXley, R. H. (2002). Do language comprehenders routinely represent the shapes of objects? Psychological Science, 13, 168-171.

ZWAAN, R. A., \& YAXLEY, R. H. (2003). Hemispheric differences in semantic-relatedness judgments. Manuscript submitted for publication.

\section{NOTE}

1. Following a suggestion made by a reviewer, we also considered potential asymmetries in associations between the "top" (e.g., branch) and "bottom" (e.g., root) words in our stimuli. That is, we examined, whether branch was more likely to prime root than vice versa. The norms for most of our stimuli were obtained from the the University of South Florida word association, rhyme, and word fragment norms (Nelson, McEvoy, \& Schreiber, 1998). For the words that could not be found in the database, associations were collected from 35 psychology graduate students in the Department of Psychology at Florida State University. As was done in the case of the Nelson norms, the students wrote the first word that came to mind that was meaningfully related or strongly associated to the presented word. For the items used in Experiments 1 and 2, the average association strength (the proportion of people who generated the target word when presented with the cue) from top to bottom words was .030 and the average association from bottom

to top words was .065 ; this difference was not significant $[t(26)=$ $-1.26, p>.20, S E=.026]$. For the items used in Experiment 3, the corresponding averages were .080 and .073 , respectively. Again, the difference was not significant $[t(62)=.32, p>.75, S E=.024]$.

\section{APPENDIX A}

\section{Word Pairs Used in Experiments 1 and 2}

airplane-runway
attic-basement
belt-shoe
boat-lake
branch-root
bridge-river
car-road
castle-moat
ceiling-floor
curtain-stage
fender-tire
flame-candle
flower-stem

hat-scarf
head-foot
headlight-bumper
hood-engine
knee-ankle
lamp-table
lid-cup
nose-mouth
roof-porch
saddle-stirrup
sheet-mattress
sky-ground
sweater-pants

APPENDIX B Word Pairs Used in Experiment 3

airplane-runway

antenna-radio

antler-deer

attic-basement

billboard-highway

boat-trailer

boot-heel

bouquet-vase

branch-root

bridge-river

car-road

castle-moat

ceiling-floor

grill-charcoal

cork-bottle

cup-saucer

curtain-stage

eyes-whiskers

faucet-drain

flame-candle

flower-stem

foam-beer

fountain-pool

froth-coffee

glass-coaster

handle-bucket

handrail-porch

head-foot

headlight-bumper

hiker-trail

hood-engine

icing-doughnut

jam-toast
jockey-horse
kite-string
knee-ankle
lid-box
lighthouse-beach
mailbox-post
mane-hoof
mantle-fireplace
mast-deck
monitor-keyboard
mustache-beard
nose--mouth
pan-stove
pedestrian-sidewalk
penthouse-lobby
pitcher-mound
plant-pot
rocket-launchpad
roof-house
runner-track
saddle-stirrup
seat-pedal
sky-ground
smoke-chimney
sprinkler-lawn
steeple-church
stoplight-street
sweater-pants
tractor-field
train-railroad

jam-toast

jockey-horse

knee-ankle

lid-box

lighthouse-beach

mailbox-post

mane-hoof mantle-fireplace mast-deck monitor-keyboard mustache-beard ose-mouth pan-stove penthouse-lobby pitcher-mound plant-pot rocket-launchpad roof-house runner-track saddle-stirrup seat-peda sky-ground smoke-chimney sprinkler-lawn steeple-church stoplight-stree tractor-field

(Manuscript received March 21, 2002; revision accepted for publication June 13, 2002.) 